\title{
DO COELHO ESPERTO À RATINHA CORAJOSA: REPRESENTAÇÕES DE GÊNERO NAS HISTÓRIAS INFANTIS DE BEATRIX POTTER
}

\author{
From the smart rabbit to the brave little mouse: \\ gender representation in Beatrix Potter's children's \\ tales
}

\author{
Beatriz Polidori Zechlinski ${ }^{l}$ \\ Stéfani Oliveira Verona ${ }^{2}$
}

\begin{abstract}
RESUMO
Os contos de Beatrix Potter, publicados na Inglaterra, no início do século XX, podem ser interpretados através da análise das representações de gênero presentes na literatura, para que as tramas e as personagens possam revelar visões de mundo construídas pela autoria feminina e para maior compreensão das transformações sociais e culturais do período. Durante a análise ficou claro que existem contradições nas representações dos papéis de gênero elaboradas pela autora, já que as mulheres foram retratadas como mães que educavam seus filhos com disciplina e com autoridade, mas sempre dentro do lar. O orgulho masculino foi demonstrado em desafio a essas figuras mais velhas, especialmente através do descumprimento de ordens, e é possível que essas passagens retratem a aspiração da autora pela igualdade entre homens e mulheres, através de seu desejo de ser vista com a mesma consideração concedida aos homens. O papel das personagens femininas ficou amplamente concentrado no ambiente doméstico, sendo que deveriam dar o exemplo de bom comportamento, gentileza e educação. As personagens masculinas, no entanto, não tinham a mesma responsabilidade e
\end{abstract}

\footnotetext{
${ }^{1}$ Doutora em História pela UFPR, professora na PUC-PR.

${ }^{2}$ PUC-PR.
} 
suas travessuras eram sempre perdoadas. Algumas das protagonistas se arriscaram, mas a autora deixou claro que para isso acontecer, elas eram obrigadas a sair de suas zonas de conforto domésticas. Considerando os ideais de gênero do início do século XX, é possível concluir que os contos de Beatrix Potter representam uma crítica à sociedade inglesa da época, que colocava os homens sempre acima das mulheres, responsáveis por protegê-las e mantê-las.

Palavras-Chave: Beatrix Potter. Representações de Gênero. Contos infantis.

\begin{abstract}
Beatrix Potter's tales, published in England, in the beginning of the twentieth century, can be interpreted through the gender analysis of the books representations, so that the stories and characters may reveal worldviews built by female authorship and for the better comprehension of the social and cultural changes of the begining of the twentieth century. During the analysis the contradiction between gender roles was clear, because women were portrayed as mothers who educate their children with discipline and authority, but always within the home. Male pride wasdemonstrated in defiance of these older figures through the noncompliance of orders, and it is possible that these passages portray the author's aspiration for equality between men and women, through her desire to be seen with the same regard than men. The role of the female characters was largely concentrated in the domestic area, for they should set an example of good behavior, kindness and education. The male characters, however, did not have the same responsibility and their antics were always forgiven. Some of the female protagonists ventured, but the author made clear that for this to happen, they were forced to leave their comfort zones at home. Considering the ideal of femininity and motherhood of the early twentieth century, it is possible to conclude that Beatrix Potter's tales represent a critique of the English society at the time, which placed men always above women and being responsible for protecting and maintaining them financially.
\end{abstract}

Keywords: Beatrix Potter. Gender Representation. Children's Tales.

Beatrix Potter foi uma autora de contos infantis que escreveu na Inglaterra, no início do século XX. Após alguns anos de dificuldades para conseguir publicar suas histórias, ela obteve significativo sucesso com o público e tornou-se uma das autoras de histórias infantis mais cultuadas da Inglaterra e do mundo. Potter 
contextualiza os seus contos em ambientes rurais, com enredos que envolvem os animais de fazenda em aventuras.

Este artigo tem o objetivo de analisar as representações sociais presentes em treze dos vinte e três contos de Beatrix Potter, publicados entre1902 e 1930, especialmente as representações de gênero, buscando demonstrar qual é a perspectiva da autora sobre as relações entre homens e mulheres e sobre a constituição da família inglesa no período. Dessa forma, buscamos refletir sobre como essas histórias podem ter influenciado na educação de crianças, tendo em vista o impacto imediato alcançado pela venda desses livros e pelo extenso número de edições que eles tiveram posteriormente.

Partimos da compreensão de que a experiência da autoria feminina naquela configuração social específica pode ter sido um fator importante na elaboração do código de condutas construído pela autora. Dessa forma, entendemos que Potter vivenciou e participou de uma "luta de representações", na qual o seu papel de autora carrega um duplo sentido. Por um lado, ela ocupa um lugar como sujeito histórico em um universo de publicações de livros dominado por escritores e editores homens, e, por outro, ela escreve histórias que permeavam as vivências familiares de leitores e de leitoras e que entrelaçavam as relações entre pais e filhos.

Assim, um dos desafios enfrentados por esta pesquisa foi o de discutir o quanto a experiência de ser uma escritora num ambiente intelectual predominantemente masculino interferiu na construção das representações que podemos perceber nessas histórias. A compreensão da "luta de representações" pela disciplina histórica, especialmente desenvolvida por Roger Chartier, ajuda-nos a entender que nenhum autor ou autora, ao criar uma narrativa e publicá-la, está isento de posicionar-se frente aos embates simbólicos do seu próprio tempo, pois os significados produzidos pela literatura podem causar uma forma de adesão ou uma reação contrária ao sentido da narrativa.

As lutas de representações são assim entendidas como uma construção do mundo social por meio dos processos de adesão ou rechaço que produzem. Ligam-se estreitamente à incorporação da estrutura social dentro dos indivíduos em forma de representações mentais, e o exercício da dominação, qualquer que seja, graças à violência simbólica. (CHARTIER, 2011, p. 22) 
Consideramos que a representação do mundo social por cada indivíduo, projetada em grupos formadores da sociedade como um todo, cria concepções que legitimam a representação. No caso das representações de gênero, essa legitimação acontece através da construção das diferenças entre o feminino e o masculino. No final do século XIX e no início do século XX, na Europa, essas diferenças de gênero eram marcadas por visões de mundo nas quais a noção de dominação associada ao masculino e a de fragilidade associada ao feminino permeavam várias esferas da vida social.

Em uma série de pesquisas que consideram o gênero como categoria de análise observa-se que no século XIX, na sociedade ocidental, houve um recrudescimento da dominação masculina e a construção de uma nova concepção do papel social das mulheres. Nesse século os discursos hegemônicos, especialmente o científico, mas também o político, o religioso e o artístico, passaram a sustentar a concepção de que a mulher era um ser que servia de complemento ao homem e que deveria ser seu subordinado (MACHADO, 1998).

A ciência moderna muito contribuiu para a inferiorização feminina, quando passou a divulgar uma percepção biologizante do corpo feminino associado à fragilidade, à fraqueza e à emoção (MARTINS, 2004). Essas ideias serviram de suporte para os discursos que pretendiam restringir a atuação das mulheres ao espaço doméstico e aos cuidados da família, e que pretendiam produzir nesse ambiente privado uma proteção para a "fragilidade" feminina (SILVA, 2000).

No campo dos Estudos de Gênero e da História das Mulheres, podemos analisar a construção desses discursos hegemônicos, como bem demonstrou Joan Scott (SCOTT, 1995), mas podemos também empreender uma análise da resistência feminina frente à dominação masculina através das representações sociais elaboradas por mulheres, em especial se olharmos com atenção para a produção de escritoras ou de artistas plásticas. As lutas de representações estão ligadas às formas encontradas por grupos sociais para manifestar sua adesão ou seu rechaço aos modos de dominação, o que frequentemente acontece através da literatura. Assim, embora possamos perceber, muitas vezes, a conivência de um escritor ou de uma escritora aos discursos hegemônicos, outras vezes o texto 
literário expressa críticas sociais ou visões de mundo não hegemônicas, conforme demonstra Nicolau Sevcenko (1985).

Adiciona-se a isso o fato de que a literatura, nas sociedades ocidentais, mostrou-se um meio muito eficaz de propagação de ideias. Com a invenção da prensa, no século $\mathrm{XV}$, o volume de estudos literários e de leitores cresceu em virtude da maior divulgação e acesso ao material escrito, além da possibilidade de várias edições da mesma obra, mas foi apenas com a passagem dos pergaminhos e escritos em rolos para os livros de páginas costuradas que ocorreu uma mudança na forma de ler os livros por parte da população. $O$ século XVIII foi marcado por essa transição, já que a partir de então as leituras, que antes eram focadas nos textos religiosos, passaram a ser caracterizadas também pela análise de jornais e de livros literários em maior quantidade (DENIPOTI, 1996).

Após o início do século XIX os gêneros literários passaram a ser mais diversificados e várias categorias surgiram para discorrer acerca de assuntos antes não escritos. A literatura infantil, assim como a literatura escrita por mulheres, apesar de serem marginalizadas, ganharam fôlego nesse século, cumprindo importantes papeis ao transmitir mensagens aos jovens leitores. A relação entre o infantil e o feminino, encontrada nas análises de gênero e de representações sociais, está igualmente presente na literatura, pois "a infância é, afinal, um estado do qual nos afastamos; livros de crianças - desde escrever para publicação à interação com crianças - são a província daquela espécie culturalmente marginalizada, a feminina" ${ }^{3}$ (DENIPOTI, 1996, p.1).

Apesar dessa visão de mundo, os livros infantis são bem sucedidos ao promover o encontro entre a teoria fantástica e o mundo real estratificado, através de alegorias e dualidades que sugerem que as noções de "infantil" e de "criança" também fazem parte da construção social de determinado grupo em determinado momento histórico, já que as histórias contidas na literatura infantil também refletem tais realidades. Em seu estudo Apontamentos sobre a

3 "Childhood is, after all, a state we grow away from; children's books - from writing to publication to interaction with children - are the province of that culturally marginalised species, the female."(DeNipoti, 1996, p.1). 
História da Leitura, Cláudio DeNipoti especifica essa marginalização das literaturas produzidas por certas representações:

A censura tende a caracterizar as crianças como impressionáveis e de mentes simples, incapazes de ter uma visão equilibrada, por exemplo, de questões sexuais ou raciais, a menos que um balanço seja explicitamente estabelecido. [...] Tentativas foram feitas para censurar ou influenciar escritores tão diversos quanto Beatrix Potter (gatinhos despidos em The Tale of Tom Kitten) ou Alan Garner (trenó sem supervisão em Tom Fobble's Day) ${ }^{4}$ (DENIPOTI, 1996, p.7).

A linguagem com a qual os escritores passam suas mensagens aos leitores e às leitoras podem revelar construções sociais através dos gêneros, etnias e religiosidades, por exemplo. Os discursos de gênero na literatura infantil, provenientes da popularização da escrita e da leitura em diversas áreas, revelam formas encontradas para tratar de assuntos de representatividade social através da discussão das questões que envolvem os significados do feminino e do masculino, não apenas em suas diferenças mas principalmente pela análise de conjunturas que envolvem ambos os sexos de maneiras diversas.

Durante o século XIX, na Inglaterra, o cenário no qual essa linguagem estava inserida era o da Revolução Industrial, dominada pelas ideias liberais e pelo crescente envolvimento da população na política britânica (RÉMOND, 1990). Entretanto, poucas das conquistas políticas se estendiam às mulheres e às crianças das classes mais baixas da população e que dependiam do trabalho para sustento. Elas também estavam sujeitas às longas jornadas: em 1838 foi constatado que $77 \%$ dos trabalhadores nas fábricas de tecidos eram do sexo feminino ou crianças.

\footnotetext{
${ }^{4}$ Censorship tends to characterise children as impressionable and simpleminded, unable to take a balanced view of, for example, sexual or racial issues, unless the balance is explicitly stated. [...] Attempts have been made to censor or influence writers as diverse as Beatrix Potter (undressed kittens in The Tale of Tom Kitten) or Alan Garner (unsupervised sledging in Tom Fobble's Day) (DENIPOTI, 1996, p.7).
} 
As operárias eram consideradas como "dóceis" pelos patrões, fáceis de manipular, acostumadas a obedecer. Essa visão era reforçada pela fraca organização sindical feminina. As tentativas de greve organizadas pelas operárias tinham pouca adesão feminina e quase nenhuma masculina, sendo rapidamente dispersadas. A mão de obra feminina era monetariamente desvalorizada e, portanto, altamente lucrativa para o seu empregador (PERROT, 2005).

A Era Vitoriana (1837-1901) coincidiu com esse período industrial na Inglaterra e foi batizada a partir do governo da rainha Vitória, tida como devota ao seu marido, o príncipe Albert, e defensora do ideal de vida doméstica que a colocou na posição de ícone de feminilidade durante o século XIX, principalmente entre as mulheres de classe média. As esferas separadas dos deveres femininos e masculinos dessa classe média posicionavam as mulheres como mães e donas de casa, enquanto os homens eram considerados responsáveis por agir no espaço público e por prover o sustento do lar.

Essa concepção já estava enraizada na Inglaterra do século XIX e início do XX, justificada, no período, principalmente na figura da rainha que viria a ser uma das governantes que mais tempo estiveram no poder. Apesar disso, muitas foram as escritoras que usaram seus trabalhos para questionar as limitações $\mathrm{e}$ a "domesticação" da "esposa ideal", ao mesmo tempo em que surgiam movimentos sociais sufragistas pelo direito ao voto feminino e à educação, tendo entre as principais bases intelectuais do movimento os escritos de Mary Wollstonecraft, que questionava essa domesticação feminina já desde o final do século XVIII (RODRIGUES, 2017).

As demandas femininas por direitos políticos originaram, com a chegada do final do século XIX, lutas pelo exercício do intelecto das mulheres em todas as áreas, assim como reivindicações por oportunidades de empregos e por uma melhor qualidade do ensino oferecido a elas, o que envolveria também a possibilidade de ingresso no ensino superior. Nesse cenário inglês de alto desenvolvimento industrial por conta da Revolução, de novas reivindicações liberais do Século Revolucionário, do surgimento dos 
sindicatos e das sufragistas, em contraste com o modelo ideal de feminilidade na figura da rainha Vitória, nasceu em Londres, no sul de Kensington, a futura escritora Helen Beatrix Potter, no ano de 1866.

Beatrix e seu irmão mais novo, Walter Bertram, cresceram na cidade, mas passavam as férias no campo, em Lake District ${ }^{5}$ e foram educados em casa por uma série de governantas que despertaram em Beatrix o interesse por literatura, estudo de línguas, folclore e contos de fadas. Ela também criou em sua adolescência um diário escrito em código entre os anos de 1881 e 1897 e que só foi decifrado em 1958. Em seus escritos pessoais ela registrava suas atividades, opiniões artísticas e costumes da sociedade, enquanto em seu livro de desenhos praticava suas observações da natureza, aspectos que mais tarde seriam fundamentais para a publicação de seus contos infantis, escritos e ilustrados por ela (LEAR, 2008).

Ao final de sua adolescência e início da vida adulta, Beatrix Potter se dedicou ao estudo analítico das plantas e dos animais, e a área de História Natural permitiu a ela maior conhecimento sobre arqueologia e geologia. $\mathrm{O}$ estudo da micologia, ou seja, análise dos fungos, principalmente no campo de Lake District, a permitiu realizar os primeiros esboços dos cogumelos Boletus granulatus, espécie que seria estudada a fundo pela ciência apenas anos depois.

Em 1901, Beatrix Potter escreveu algumas cartas ilustradas para crianças que eram próximas de sua família, essas cartas tiveram como resultado as origens do seu primeiro livro: The Tale of Peter Rabbit $^{6}$, impresso e publicado pela primeira vez por ela mesma. Apenas mais tarde, em 1903, Norman Warne editaria seus próximos livros The Tale of Squirrel Nutkin ${ }^{7}$ e The Tailor of Gloucester ${ }^{8}$, em agosto e outubro, respectivamente. Até o ano de 1906, devido ao sucesso dos livros lançados, Beatrix escreveu mais vinte histórias infantis e consagrou sua independência financeira em 1909, quando comprou sua segunda propriedade, Castle Farm.

\footnotetext{
${ }^{5}$ Distrito do Lago (Tradução Livre da autora).

${ }^{6}$ As Aventuras de Pedro Coelho.

${ }^{7}$ A História do Esquilo Nutkin.

${ }^{8} \mathrm{O}$ Alfaiate de Gloucester.
} 
Em 1913, aos quarenta e sete anos, casou-se com William Heelis e continuou a escrever até 1930, quando produziu seu último conto infantil: The Tale of Little Pig Robinson ${ }^{9}$, editado e publicado pela Frederick Warne \& Co. Beatrix Potter Heelis morreu em 22 de dezembro de 1943, deixando quinze fazendas e mais de quatro mil acres para o National Trust, organização britânica para cuidado de imóveis campestres e jardins, de forma a proteger e conservar o campo de Lake District, memória também contida em seus vinte e oito livros ilustrados, que foram traduzidos para mais de trinta e cinco línguas e que traziam o Distrito como cenário.

Com o advento dos estudos de gênero e das representações sociais contidas nas manifestações culturais, análises dos contos infantis de Beatrix Potter foram feitas para interpretação de suas ideias e da sociedade da época vitoriana. Alguns estudos apresentam divergências principalmente ao descrever a relação da autora com os animais, especialmente em sua infância e adolescência.Segundo o Victoria and Albert Museum, em uma matéria publicada em seu site oficial em 2016, Beatrix e seu irmão Walter dedicavam horas observando e desenhando apaixonadamente sua coleção de animais, a qual incluía sapos, tartarugas, salamandras e um morcego. Já Gillian Avery, em seu estudo Beatrix Potter and Social Comedy (1992), aponta que Beatrix mantinha interesse apenas científico por eles ao registrar seus comportamentos e hábitos, sem sentimentalismo. Como exemplo é colocado a sua falta de comoção com o falecimento do cavalo da família, além de seu desgosto por cachorros, expresso em seu diário (mesmo que depois tenha obtido um). Apesar disso, Avery assume estar ciente do gosto de Beatrix por esquilos e coelhos, personagens centrais de suas histórias infantis.

O período vitoriano permitiu aos escritores da época traduzir em seus textos as representações da realidade e, dessa forma, suas preocupações sociais poderiam servir de parâmetro para a experiência da realidade presente na elaboração ficcional dos livros. A literatura infantil não está isenta desse efeito, como afirma Mandy DeWilde:

${ }^{9} \mathrm{O}$ Conto do porquinho Robinson. 
Desde o nascimento das Fábulas de Esopo, animaispersonagens frequentemente foram incluídos na literatura infantil e utilizados como um meio para contos de moralidade. É através de maior consideração e exploração que essas histórias propiciam aos leitores mais do que apenas um bom entretenimento à moda antiga [...] mas, muitas vezes, um comentário social e cultural mais profundo e mais pensativo. Os contos de Potter fazem exatamente isso. ${ }^{10}$ (DEWILDE, 2008, p. 2).

Os principais estudiosos de Beatrix Potter apontam também para a representatividade humana das personagens animais contida em suas vestimentas, tendo em vista que quanto mais elaboradas as roupas são, mais personalidade humana tem o animal. Dessa forma, aqueles sem roupa alguma, como o gato do Sr. McGregor em Peter Rabbit, não são dotados das características dos seres humanos, como a fala, casa e organização de suas tarefas. Essas propriedades características são representadas especialmente pelas figuras das mães dos personagens principais, já que, vestidas como mulheres das classes médias, elas são pessoas inseridas na sociedade e buscam conter os instintos naturais de seus filhos através do confinamento de suas vestimentas, com muitas camadas e botões.

Segundo o estudo de DeWilde (2008), a própria Beatrix Potter teria se sujeitado às vontades de seus pais, como esperado dela, de maneira a manter seus interesses pessoais para si, e sendo uma criança curiosa, teria usado sua própria vida como fonte de inspiração para suas histórias.

A ilustração de Potter da mãe de Pigling Bland enrolando o lenço laranja firmemente ao redor de seu pescoço era talvez o gesto de Potter de se sentir estrangulada por sua própria mãe obstinada e egocêntrica. Outras formas de mães confinando e

${ }^{10}$ From the birth of Aesop's Fables, animal-characters have often been included in children's literature and used as a medium for morality tales. It is upon further consideration and exploration that these stories provide readers with more than just good old-fashioned entertainment and finger-wagging warnings, but often a deeper, more thought-provoking social and cultural commentary. Potter's tales do exactly this. 
apertando seus filhos são abundantes em ilustrações para seus contos. ${ }^{11}$ (DEWILDE, 2008, p.10).

DeWilde defende que Beatrix Potter teria usado as roupas que seus pais designavam por respeito às ocasiões formais, mas que não gostava da frivolidade dos arranjos femininos e das camadas de saias, de forma que existiria a possibilidade de Potter ter usado sua própria personalidade em seus contos, além de ter sido bem sucedida ao criticar a restrição de sua época e se colocar na figura de um personagem masculino.

Em seu estudo, Guijarro (2010) também aponta para o realismo nas ilustrações, de forma a revelar o talento de Beatrix Potter em sua criatividade artística, combinada com a precisão científica. Os objetos desenhados de forma muito semelhante aos reais, as roupas das personagens e suas casas também revelam a preocupação com o cenário a partir da representação inglesa. Guijarro também afirma que ao ilustrar os livros para que as personagens principais olhem diretamente para o leitor, é possível constatar a intenção de Potter quanto a uma "forte identificação entre herói e espectador" 12 (GUIJARRO, 2010, p.139), de maneira a desenvolver maior empatia pela história e assimilação de seu conteúdo.

Alexandra Jeikner acrescenta em sua tese de doutorado o desejo feminino de emancipação contido nos contos de Beatrix, especialmente na figura de Ribby em The Tale of Samuel Whiskers ${ }^{13}$ (1908), uma gata que tem sua realidade centrada dentro de sua casa, mas que demonstra vontade de fazer novas amizades, mesmo não tendo coragem para tal. A falta de persistência feminina também está contida em Jemima, em The Tale of Jemima Puddle-Duck ${ }^{14}$ (1908), que, apesar de ser uma das poucas protagonistas femininas, tem sua busca por representatividade reduzida por sua ingenuidade. A representação da imposição social de gênero presente em Jemima

${ }^{11}$ Potter's illustration of Pigling Bland's mother wrapping the orange scarf tightly around his neck was perhaps Potter's gesture of feeling strangled by her own constricting and egocentric mother. Other forms of mothers constricting and confining their children are abundant in the illustrations for her tales.

${ }^{12}$ strong engagement between the hero and the viewer.

${ }^{13} \mathrm{O}$ Conto de Samuel Whiskers.

${ }^{14}$ O Conto de Jemima Pudle-Duck. 
remete-nos ao ressentimento demonstrado por Beatrix quanto à privação dos direitos das mulheres. Em 1910 ela protestou em favor do direito ao voto feminino, assim como contra as cláusulas de taxação de terras, e desde 1909 ela havia se emancipado financeiramente de sua família, sendo que se casaria apenas em 1913 (JEIKNER, 2014).

Beatrix Potter representa em suas histórias a sociedade patriarcal inglesa do início do século XX através das ações dos personagens masculinos, tanto os adultos quanto as crianças, que encontram maneiras de livre expressão e desobediência recompensadora através de suas aventuras. Essas ações são negadas às personagens femininas, às quais faltam coragem e decisão. A elas é reservado o espaço doméstico conservador, que, assim como as vestimentas, revelam a diferença de gênero contida na sociedade da qual Beatrix Potter fazia parte, tendo em vista que as relações humanas em sociedade formam o caráter pessoal que pode ser traduzido na produção literária.

Os enredos de seus contos são acompanhados de ilustrações feitas majoritariamente pela própria escritora e de algumas outras feitas por editores que a auxiliaram com o passar do tempo. Dessa forma, é importante analisar essas imagens considerando-as não apenas ilustrativas, mas auxiliares na construção da narrativa do texto escrito e nas mensagens a serem passadas às crianças. De acordo com Edward Parker "Beatrix Potter foi uma das primeiras ilustradoras a planejar cada detalhe de produção e layout em um livro" 15 (PARKER, 1969, p. 8). As ilustrações demonstram características das vestes e aparências dos personagens, assim como seus afazeres, e em diversos momentos revelam traços de suas personalidades.

As imagens também situam o cenário que acaba sendo familiar às crianças, já que Potter misturou a fantasia dos animais falantes com o cenário realista rural inglês, de forma que esses dois universos se completaram a partir da imaginação infantil. Da mesma maneira, os animais se tornam ainda mais familiares às crianças ao demonstrarem habilidades humanas e vestimentas do mesmo período

\footnotetext{
${ }^{15}$ Beatrix Potter was one of the first illustrators to plan every detail of production and layout in a book (PARKER, 1969, p. 8).
} 
em que as histórias foram escritas, criando um antropomorfismo que torna a crença das crianças na história confortável. Beatrix Potter utiliza esse aspecto para tornar mais fácil a identificação das crianças com seus personagens (DUAN, 1994).

Dessa forma, é importante buscar este e outros motivos que levaram a autora a inserir sua fantasia em cenários do mundo real ao invés de construir novas paisagens não existentes para realizar suas tramas, assim como suas motivações para escolha do campo como cenário, ao invés das cidades que passavam pela industrialização da grande Revolução na Inglaterra. Como afirma Vasconcelos,

Levar em conta a importância das ilustrações para a literatura infantil exige compreender, com base no destacado por Lima (2008, p. 37), que elas se situam dentro de um todo, o design gráfico do livro infantil, o qual envolve um conjunto de elementos gráficos que, organizados de maneira harmônica, exercem influência no modo como a narrativa será recebida pelos leitores e contribuem para a formação do olhar estético dos mesmos (VASCONCELOS, 2014, s. pág.).

A escolha de animais ao invés de pessoas poderia auxiliar em possíveis objetivos de "lições morais para as crianças" através de "propósitos didáticos" 16, como defendido por Duan em sua dissertação The Changing Images of Animals in Animal Fantasy for Children(1994, p. 3). Como também aponta Peter Hunt, "nas fantasias, os animais podem evoluir para cima, tornando-se mais humanos, enquanto os seres humanos degeneram em animais" 17 (HUNT, 2002, p. 74). Sendo assim, a análise da relação que as crianças tinham com os animais durante o início do $\mathrm{XX}$ é significativa.

Da mesma maneira é possível identificar alguma forma de crítica quanto aos padrões estéticos da época vitoriana, especialmente na relação entre as mulheres e a forma como se mostravam em sociedade e como se comportavam. Segundo Marjorie Weir, "A frustração das capacidades, a oportunidade limitada para a realização

\footnotetext{
16 "Moral Lessons for the Child" e "Didactical Purposes" (DUAN, 1994, p. 3).

${ }^{17}$ In the fantasies, animals can evolve upwards, becoming more human, while human beings degenerate into animals (HUNT, 2002, p. 74).
} 
intelectual, a escassez de companheiros agradáveis - todos esses fatores contribuíram para o que Barbara Hardy chama a 'deficiência'de ser uma mulher no século XIX"18 (WEIR, 1989, p. 127).

Weir expressa a possível situação de descontentamento das mulheres do século XIX com relação a diversos fatores, entre eles a falta de oportunidades para realização intelectual, algo que ela também coloca como importante na vida de Beatrix Potter, particularmente após os primeiros indícios do sucesso de seu primeiro conto publicado, The Tale of Peter Rabbit (1902): "Na maior parte, Potter adere aos estereótipos sexuais - os personagens masculinos são muitas vezes criaturas calculadoras, sujas e agressivas do exterior, enquanto as fêmeas são inocentes, arrumadas e obcecadas com as tarefas domésticas" ${ }^{19}$ (WEIR, 1989, p. 149-150).

Os contos de Beatrix Potter são estruturados através de imagens e passagens escritas sucintas, na maioria das vezes consistindo em apenas algumas frases que acompanham as ilustrações. Em alguns casos, porém, como em The Tailor of Gloucester, as partes escritas são mais numerosas, mas sempre aparecem de forma simples para atingir maior conexão das histórias com os pequenos leitores. As histórias são curtas e apresentam personagens que reaparecem em diversos contos, sugerindo que o universo criado conecta as narrativas em um único espaço, o rural.

Os personagens são retratados de forma realista em suas características físicas e a autora especifica as comidas que mais gostam e os lugares onde vivem. Apesar disso, durante os contos ela apresenta aos leitores os mesmos animais de forma "humanizada", ao vesti-los, apresentá-los com hábitos de cozinhar e limpar a casa, andar em duas patas e constituírem famílias no modelo das inglesas. Através de suas falas e da maneira como se comportam é feito um paralelo entre a realidade física dos animais e seus hábitos naturais de

18 The frustration of capabilities, the limited opportunity for intellectual achievement, the dearth of congenial companions--all of these factors contributed to what Barbara Hardy calls the "disability" of being a woman in the nineteenth century (WEIR, 1989, p. 127).

19 for the most part, Potter sticks to sexual stereotypes-male characters are often calculating, dirty, aggressive creatures of the outdoors, while females are innocent, tidy, and obsessed with housework (WEIR, 1989, p. 149-150). 
alimentação (através da representação realista nas imagens) e entre a imaginação infantil das crianças (que também encontram nas mesmas imagens os animais "humanizados").

Em algumas das imagens produzidas por Potter, como, por exemplo, a ilustração da ratinha Tiddlemouse, em The Tale of mrs. Tiddlemouse ${ }^{20}(1910)$, é possível encontrar a relação entre o tamanho da personagem apresentada e o que ela representa, já que Tiddlemouse é uma das poucas protagonistas, mas é retratada de forma tão pequena que as abelhas e joaninhas são maiores do que ela em algumas imagens. Esse aspecto pode estar relacionado à fragilidade que a figura feminina representaria no início do século $\mathrm{XX}$, figura que não contava com ampla independência e que estava conectada de maneira extensa a sua casa.

Do ponto de vista pessoal, esses dois aspectos foram desafiados por Beatrix, que, justamente devido à publicação dos seus contos, alcançou a independência financeira e se casou tarde para os padrões da época. Todavia, suas histórias sugerem que apesar de sua própria condição, a autora estava ciente da realidade das mulheres inglesas do início do século XX. As vestes da Sra. Tiddlemouse, por exemplo, levam-na a representar o ideal da dona de casa do ambiente rural, estando em diversas ocasiões com sua cesta e sendo caracterizada por seu avental.

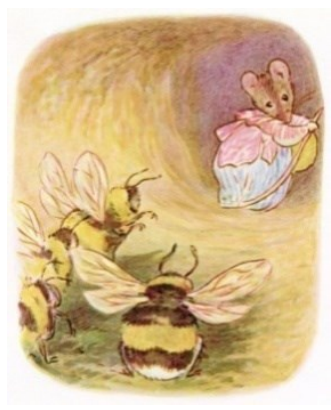

${ }^{20} \mathrm{O}$ Conto da Sra.Tiddlemouse. 
Durante grande parte da narrativa, Beatrix Potter enfatiza a descrição dos cômodos da casa e o costume da Sra. Tiddlemouse de mantê-la constantemente impecável, algo que era também esperado das donas de casa inglesas do início do século XX, assim como seu perfeccionismo, que a leva a percorrer grandes distâncias em busca de ingredientes para suas comidas. Suas características revelam impaciência em diversas ocasiões quanto a outros animais que não se mostram tão organizados ou limpos: "Não receberei o Sr. Jackson; ele nunca limpa os pés" ${ }^{21}$ (POTTER, 1910), mas sua educação caseira a leva a receber o personagem sapo mesmo a contragosto. Essas características da vida doméstica não estão presentes nos contos protagonizados por personagens masculinos e mesmo a figura do Sr. Jackson é retratada como dominante na casa da Sra. Tiddlemouse, a quem ele chama de "pequena" 22 (POTTER, 1910).

Em The Tale of Jemima Puddle-Duck (1908), Beatrix Potter também apresenta uma personagem vestida como uma senhora do ambiente rural, de touca e capa sobre os ombros. Logo no início da narrativa, a pata Jemima está brava com a esposa do fazendeiro, que não a deixa chocar seus ovos, e sua consciência, que a coloca mais próxima dos seres humanos, é retratada também em suas relações familiares, já que ela tem também uma cunhada, algo inexistente no mundo animal. Sua insistência em criar os filhos retrata a responsabilidade rural inglesa das mulheres do século $\mathrm{XX}$, e sua determinação e cuidado são enfatizados na narrativa do conto.

Apesar disso, sua ingenuidade não a deixa desconfiar de uma raposa que encontra no campo e que é definida na narrativa como um "cavalheiro hospitaleiro"23 (POTTER, 1908).O caráter duvidoso da raposa é exposto ao leitor através de uma ilustração, quando o "cavalheiro" lhe oferece a casa para que ela cuidasse de seus ovos.

A raposa encontra então oportunidade para se apossar dos ovos com a saída de Jemima da casa e suas intenções são reveladas quando a autora a ilustra sem suas roupas, ou seja, "desumanizada" e provida apenas de seus instintos, bisbilhotando o ninho de Jemima.

\footnotetext{
21 "I will not have mr. Jackson; he never wipes his feet" (POTTER, 1910).

22 Tiddly, widdly, widdly (POTTER, 1910).

23 "Hospitable gentlemen" (POTTER, 1908).
} 
Esses instintos característicos dos animais são revelados fora do convívio social e em momentos de descontrole, pois a boa convivência e as representações sociais eram também as regras da sociedade inglesa de Beatrix Potter.

No mundo convencional dos livros ilustrados para crianças, o estado dos animais que falam como seres humanos é uma metáfora para o estado de infância humana, no qual as crianças devem aprender a negociar entre os impulsos de animais de seus desejos corporais e as demandas dos adultos, que eles reprimem o desejo e se comportam de maneiras sociais aceitáveis - isto é, como os humanos adultos ${ }^{24}$ (HUNT, 2002, p.76).

A metáfora pode ser aplicada à realidade das mulheres inglesas da sociedade na qual Potter vivia, pois a autora constrói uma representação crítica da visão tradicional do feminino em suas histórias, já que, como veremos, embora o tradicional apareça nas histórias, ele pode ser visto como fonte de muitos problemas. "Ela [Beatrix Potter] reconhece suas próprias capacidades: 'Eu acho que poderia ter sido ensinada qualquer coisa se eu tivesse sido pega jovem', ela confiou a seu diário, 'mas... apenas meninos foram para a escola na maioria das famílias"” ${ }^{25}$ (WEIR, 1989, p.129).

A ingenuidade da personagem Jemima a leva então a ficar sem seus ovos, já que alguns cachorros os atacam e matam a raposa, de forma que apenas ao final da narrativa é permitido a ela manter suas novas crias. Dessa forma, por mais persistente que Jemima tenha sido ao tentar manter seus ovos, apenas com a permissão de outro foi possível para ela exercer a maternidade, algo que ela considerava natural desde o início.

Em The Tale of Peter Rabbit (1902) o posicionamento de Beatrix Potter através de seus personagens é mais complexo, pois ao

\footnotetext{
${ }^{24}$ In the conventional world of children's picture books, the state of animals who talk like humans is a metaphor for the state of human childhood, in which children must learn to negotiate between the animal-like urges of their bodily desires and the demands of adults that they repress desire and behave in social acceptable ways - that is, as adult humans do. (HUNT, 2002, p.76).

${ }^{25}$ She recognized her own capabilities: 'I fancy I could have been taught anything if I had been caught young,' she confided to her journal, but...only boys went to school in most families" (WEIR, 1989, p.129).
} 
mesmo tempo em que alguns autores defendem que Beatrix teria inspirado o coelho Peter em si mesma (DeWilde, 2008), percebemos que ela reforça os papéis de gênero durante a história, aos quais também estava sujeita no início do século XX. Apenas Peter tem uma aventura na história e sua mãe está sempre de avental e cuidando da casa com suas irmãs.

A representação de gênero pode ser encontrada em todos esses personagens. A colocação da mãe de Peter na história está de acordo com "o cenário histórico da mulher inglesa no século XIX", que "aponta um caráter totalmente utilitarista da condição feminina imposto pela ética vitoriana" (DIAS, 2013, p.150). Isso quer dizer que "as senhoras da época eram verdadeiras 'rainhas do lar', sendo que o máximo de capacidade que as mulheres deveriam ter era a de incutir os valores morais nos filhos" (DIAS, 2013, p.150). A Sra. Rabbit é sempre retratada dando orientações aos filhos e mantendo-os bem arrumados, especialmente por conta de sua responsabilidade de tomar conta deles sem a presença do marido.

Sofie Vriends, em sua análise sobre o discurso de Beatrix Potter defende que "os desenhos e pinturas que Potter desenhou parecem dar uma perspectiva tradicional da vida, como retratam papéis tradicionais de gênero e temas" ${ }^{26}$ (2015, p.55), e continua identificando que

Em Peter Rabbit, Peter e suas irmãs são identificados por seus casacos: Peter usa uma jaqueta azul, as meninas vermelhas. Os papéis de gênero também são majoritariamente tradicionais. A maioria das mulheres é retratada em casa, além da mãe de Peter, que tem que ganhar a vida porque o pai de Peter está morto e Jemima PuddleDuck. Potter parece atribuir algum valor à domesticidade. Isso também é aparente em The Tale of Two Bad Mice, onde Hunca Munca é quem pensa na casa ${ }^{27}$ (VRIENDS, 2015, p.55).

\footnotetext{
${ }^{26}$ The drawings and paintings that Potter drew seem to give a traditional perspective on life, as they portray traditional gender roles and themes.

${ }^{27}$ In Peter Rabbit, Peter and his sisters are identified by their coats: Peter wears a blue jacket, the girls red ones. Gender roles are also mostly traditional. Most of the woman are portrayed around the home, besides from Peter's mom, who has to make a living because Peter's dad is dead, and Jemima
} 
Esta é também a ideia nos estudos de DeWilde (2008), que colocam as representações de gênero como críticas nos contos de Potter. De acordo com a pesquisadora, apenas os homens eram autorizados a realizar as aventuras criadas nas histórias e ao se arriscarem e desobedecerem às ordens, eram perdoados, algo muito menos provável de acontecer com o sexo feminino na sociedade inglesa do século XX. Em conformidade com DeWilde (2008) e Vriends (2015) sobre as representações sociais de Beatrix, Guijarro afirma

O conto (The Tale of Peter Rabbit) foi destinado para crianças da classe média inglesa na era Vitoriana, caracterizada pelas maneiras rígidas e conservadoras na corte e na educação das crianças. Em concordância com a literatura moralizadora destinada às crianças com a qual Potter estava familiarizada, a autora, que também trabalha como ilustradora, sem dúvida seguiu os requerimentos ideológicos do período Vitoriano ${ }^{28}$ (GUIJARRO, 2010, p.124).

A representação está também contida no desafio de Peter perante as orientações de sua mãe, ao desobedecê-la e aventurar-se no jardim do Sr. McGregor, mesmo lugar em que seu pai foi pego. Peter também é descrito como "muito travesso" ${ }^{29}$, enquanto suas três irmãs são "boas coelhinhas" 30 (POTTER, 1902), o que demonstra ao mesmo tempo a conformidade das figuras femininas em manter-se reservadas e o desafio da figura masculina quanto à orientação dada. Seu orgulho é demonstrado quando ele come os vegetais do $\mathrm{Sr}$. McGregor até sentir-se mal e sua punição continua quanto é perseguido e chega em casa com dificuldades.

Puddle-Duck. Potter seems to assign some value to domesticity. This is also apparent in The Tale of Two Bad Mice, where Hunca Munca is the one who thinks of home.

${ }^{28}$ The tale was intended for children of the English middle class in the Victorian era, characterized by strict and conservative manners in court and in children's education. In line with the moralising literature addressed to children that Potter was familiar with, the author, who also doubles as illustrator, no doubt followed the ideological requirements of the Victorian period.

${ }^{29}$ Very Naughty (POTTER, 1902).

${ }^{30}$ Good little bunnies (POTTER, 1902). 
Essa punição pode ser interpretada como crítica à desobediência masculina de Peter frente a sua mãe, mas a recompensa de suas irmãs por terem se comportado também revela as características esperadas das jovens. Elas não têm grande participação no enredo, mas Beatrix Potter as coloca no começo do conto e termina sua história narrando o jantar delas, possivelmente de forma a chamar a atenção do leitor para o papel feminino de bom comportamento ao qual elas estavam sujeitas. Segundo Marjorie Weir, "Frustrada em seus estudos científicos e privada de afeição e companheirismo, Potter dificilmente poderia ser culpada por ver seu 'aprisionamento' como mais real que fictício" ${ }^{11}$ (WEIR, 1989, p.135).

Durante a fuga de Peter do jardim do Sr. McGregor, ao ver-se perdido, ele "chora muitas lágrimas" 32 (POTTER, 1902), ou seja, é punido por seu orgulho e seu desafio iniciais ao contrariar sua mãe e comer os legumes do jardim. As ilustrações mostram o amplo espaço que ele percorreu em sua aventura e sua liberdade em seus passeios, enquanto suas irmãs e sua mãe permaneciam perto e dentro da casa, possivelmente de maneira a retratar a proteção do lar para as mulheres e as possibilidades de exploração do mundo para os homens.
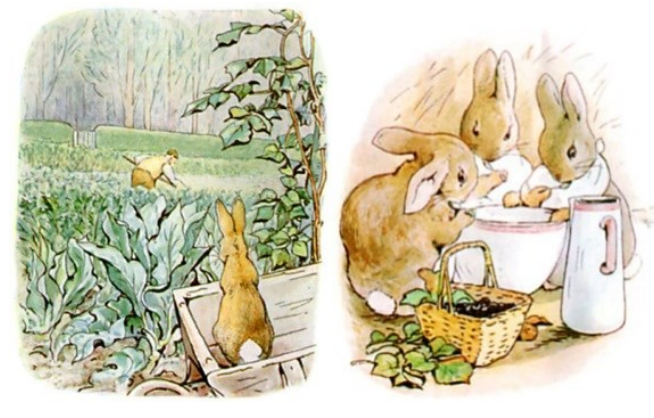

31 Frustrated in her scientific studies and deprived of affection and companionship, Potter could hardly be faulted for seeing her "imprisonment" as more real than mythic (WEIR, 1989, p.135).

${ }^{32}$ Shed big tears (POTTER, 1902). 
Beatrix Potter criou então uma história para o primo de Peter Rabbit, The Tale of Benjamin Bunny ${ }^{33} \mathrm{em} 1904$, que trouxe novamente a família Rabbit para uma narrativa. No início do conto a mãe de Peter é novamente descrita como viúva e mulher organizada que mantém a casa muito limpa. Ela pede para uma das filhas ajudá-la na cozinha, ajuda esperada apenas das moças, enquanto os primos saem novamente para a fazenda do Sr. McGregor para tentar recuperar as roupas de Peter.

Essa tentativa de recuperação é também a tentativa orgulhosa dos coelhos de desafiar o fazendeiro e a mãe de Peter, que já o havia avisado para não ir à fazenda. Os coelhos tentam trazer novamente a condição inicial do seu próprio conto, frente a qual ele se encontra na narrativa de Benjamin Bunny, sem sua identidade identificada pelas roupas, o que o diferencia de suas irmãs, pois seu casaco é azul e os delas, vermelhos. Apesar de conseguirem as roupas, Peter sugere que voltem para casa, mas demoram mais de cinco horas devido a uma gata em seu caminho.

É possível que a gata possa ser interpretada como forma de punição aos coelhos que voltaram à fazenda do Sr. McGregor e roubaram também alguns de seus legumes, e a gata aparece como figura feminina. Ela não tem nenhuma fala e é desprovida de personalidade "humana", algo representado por sua falta de vestimenta. Os coelhos só são salvos pelo pai de Benjamin Bunny, retratado como figura autoritária que assusta a gata e os liberta, para puni-los de forma severa. Essa punição empreendida pelo pai contrasta com a atitude da mãe de Peter, que o perdoa logo depois, o que demonstra determinação maior da figura masculina Apesar disso, a mãe de Peter o coloca para ajudar uma de suas irmãs e pendura os legumes roubados no teto da casa, fora do alcance dele, demonstrando também autoridade quando o priva de usufruir de sua conquista de forma sutil. O trabalho doméstico é rotineiro para as mulheres, mas incomum para Peter.

Em outro conto publicado em 1904, The Tale of the Two Bad Mice $^{34}$, Potter insere três figuras femininas e uma masculina. É

\footnotetext{
${ }^{33} \mathrm{O}$ Conto de Benjamin Bunny.

${ }^{34} \mathrm{O}$ Conto dos dois ratos maus.
} 
interessante constatar que duas dessas figuras femininas eram bonecas inglesas vivendo em sua casinha de bonecas, e descritas como muito delicadas. Os outros personagens são dois ratos, um casal, que se aproveitam da ausência delas para tentar comer na casa, mas não conseguem, pois os alimentos são de mentira.

O temperamento dos ratinhos é demonstrado quando perdem a paciência tentando comer algo duro demais: "Não havia fim para a fúria e desapontamento de Tom Thomb e Hunca Munca" ${ }^{35}$. É constatado então que eles destroem a casa e tentam levar todo o possível, sendo que a ratinha Hunca Munca leva panelas, potes, uma cama de bebê e algumas roupas de uma das bonecas, de forma que os utensílios e roupas marcam a transição nas ilustrações. A partir de então a ratinha passa a ser retratada como mãe e delicada dona de casa. O ratinho Tom Thumb, apesar de ter quebrado muitas coisas, ao final da história paga por tudo e sua esposa limpa a casa que destruíram. Essa é a representação dos papéis tradicionais da família inglesa do início do século XX: o marido responsável pelo papel de provedor, enquanto a esposa pelos cuidados da casa.

Durante toda a narrativa os aspectos humanos circulam o cenário e tomam conta dos ratinhos através da possessão dos objetos das bonecas. É também importante constatar a sutileza de Beatrix Potter em uma das cenas na qual uma das bonecas sugere à outra vestir-se de policial para pegar os ratinhos, de forma que a inversão dos papéis de mulher e de homem seria necessária para intimidar os animais, especialmente por conta da figura de autoridade pública ser um cargo masculino na sociedade inglesa daquele período.

Já em The Tale ofmrs.Tiggy-Winkle ${ }^{36}$ (1905), é retratada novamente a figura feminina através de uma "senhora ouriço" de características físicas e vestimentas clássicas da época vitoriana entre as donas de casa, e ao contrário de seus contos que trazem personagens principais masculinos, a menina Lucie, que é uma personagem mais nova, aparece na narrativa como "uma boa menininha" ${ }^{37}$ que vivia em uma fazenda chamada "Pequena-cidade" 38

\footnotetext{
35 "There was no end to the rage and disappointment of Tom Thumb and Hunca Munca" (POTTER, 1904).

${ }^{36} \mathrm{O}$ Conto da Sra. Tiggy-Winkle.

37 "A good little girl” (POTTER, 1905).
} 
e que constantemente perdia seus pertences. Nos contos de Peter Rabbit (1902) e Benjamin Bunny (1904), os coelhos eram representados como aventureiros, mas Lucie sai em sua busca pela vizinhança devido à perda de seus lenços, perdidos por descuido.

A casa da Sra. Tiggy-Winkle também é descrita como muito limpa e bem cuidada e suas habilidades com tecidos são destacadas durante a história, assim como sua hospitalidade ao oferecer chá. Ao adentrar na casa da Sra. Tiggy-Winkle, a aventura de Lucie se torna explorar o ambiente, ao contrário das personagens masculinas das narrativas de Potter, que estão em contato constante com a natureza e desafiando as regras de convivência. Esse comportamento mais liberado pode ser encontrado em The Tale of the Squirrel Nutkin(1903), por exemplo, narrativa de apenas personagens masculinos e que tem como protagonista um esquilo muito enérgico e aventureiro, mesmo que ao final acabe sendo punido por sua falta de educação com a coruja mais velha.
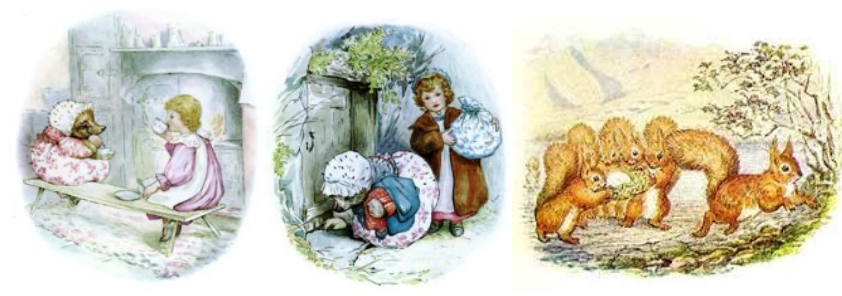

A linguagem usada tanto por Lucie quanto pela Sra. TiggyWinkle reflete a boa educação e a polidez esperada das mulheres inglesas, jovens ou mais velhas e, durante a história, ambas são retratadas com muitas roupas, revelando o caráter conservador de vestimenta mesmo dentro de casa. Já o esquilo Nutkin, em seu conto, irrita uma coruja diversas vezes devido à sua falta de educação e insistência em enigmas, índole retratada também a partir das ilustrações que o mostram sem roupas, ou seja, sem o caráter

38 "Little-town" (POTTER, 1905). 
"humanizador" e "civilizatório" utilizado por Potter, mas que justifica seu entusiasmo juvenil masculino.

A punição presente em diversos dos contos com relação ao mau comportamento das personagens masculinas pode ser interpretada tanto como crítica pessoal da autora em relação às liberdades dos homens no período vitoriano na Inglaterra, quanto como "moralização" presente nas histórias infantis, que buscavam educar as crianças para que obedecessem aos seus pais e tivessem uma boa educação. Em 1903, Beatrix Potter publicou The Tailor of Gloucester $^{39}$, no qual o alfaiate recebe sua recompensa por libertar os ratinhos presos por seu gato, que o acabam ajudando a terminar seu trabalho com os tecidos. Sua boa índole ao libertar os menores animais e menos prováveis de poder ajudá-lo o coloca na posição de ser recompensado ao final do conto, algo com o que as crianças deveriam se identificar.

Por outro lado, a crítica de Potter com relação às representações do feminino e do masculino no período em que escreveu seus contos pode ser encontrada na The Story of Miss Moppet $^{40}(1906)$. A narrativa começa apresentando os personagens: miss Moppet, uma gatinha que usa apenas um laço no pescoço, e o Rato, bem menor do que ela, mas que é ilustrado com roupas. Durante a narrativa o Rato debocha de Moppet por não conseguir pegá-lo, mesmo sendo pequeno, demonstrando ao leitor o quão esperto ele é. A gatinha então prepara uma armadilha e consegue pegá-lo, fingindo estar doente e enganando o ratinho. Apesar disso, ao final da história ele consegue novamente fugir, sem que ela perceba, enganando-a de novo.

A história é curta, mas a disputa entre as duas personagens demonstra também a competição entre domínios presente naturalmente entre um gato e um rato, mesmo representados de maneira humanizada por suas roupas. Essa disputa natural do mundo animal poderia ter sido traduzida no contexto social no qual a autora viveu como forma de crítica ao domínio masculino, conseguido ao final da história pelo Rato, considerando que, apesar de maior e

\footnotetext{
${ }^{39} \mathrm{O}$ alfaiate de Gloucester (1903).

${ }^{40} \mathrm{~A}$ História da senhorita Moppet.
} 
naturalmente predadora, a gatinha não era tão esperta quanto ele. Essa demonstração de falta de esperteza da gata estaria conectada com o fato de que os homens eram vistos na sociedade como superiores intelectualmente, independentemente das adversidades apresentadas.

Em The Tale of Tom Kitten ${ }^{41}$ (1907), Moppet aparece novamente, dessa vez mais jovem, e a figura feminina central é sua mãe, principal responsável por tornar os três gatinhos da história "apresentáveis" e "limpos", pois zela pela educação deles. Ela está completamente vestida e dá banho nos gatinhos para também vestilos, tirando-os assim de suas brincadeiras do lado de fora da casa.

$O$ fato das roupas não servirem em Tom Kitten pode funcionar como alusão à transição das crianças nas casas inglesas, quando suas brincadeiras não eram mais tão livres e elas deveriam aprender a se comportar em sociedade, algo retratado no conto pela preparação dos gatinhos para uma visita de amigas da Sra Tabitha. Apesar disso, durante a história, fica claro que esse processo não é natural, tendo em vista que os gatinhos acabam brincando e se desfazendo das roupas, voltando assim ao conforto habitual.

A responsabilidade da mãe dos gatinhos quanto à sua boa apresentação a força a mentir para suas amigas e escondê-los, estando apenas ela apresentável. Durante o conto os cenários são divididos entre a casa e os jardins, sendo que, durante a estadia dos gatinhos em casa, eles são forçados a obedecer e vestir-se de forma não natural, ao contrário de quando estão ao ar livre. Essas passagens podem fazer relação com a vida de Beatrix Potter no campo, onde as regras de etiqueta eram mais livres. Ao mesmo tempo, porém, podem servir como forma da autora escapar de sua "tediosa rotina diária nos jardins de Bolton" 42 (WEIR, 1989, p.162), através das aventuras dos gatinhos.

A figura feminina que consegue destacar-se por salvar os filhotes de Benjamin Bunny é a Sra. Tiddlemouse, que retorna em The Tale of the Flopsy Bunnies ${ }^{43}$ (1909), e protagoniza a correção do erro de Benjamin ao deixar que seus filhos comessem da plantação do

\footnotetext{
${ }^{41} \mathrm{O}$ Conto do gatinho Tom.

42 "tedious daily routine at Bolton Gardens" (WEIR, 1989, p.162).

${ }^{43} \mathrm{O}$ Conto dos coelhinhos Flopsy.
} 
Sr. McGregor, como havia feito com seu primo Peter Rabbit em The Tale of Benjamin Bunny, de 1904. Apesar disso, a escolha da autora de colocar a Sra. Tiddlemouse, uma ratinha, para ajudar os coelhos a escapar de uma armadilha, pode revelar sua crítica quanto à posição feminina, tendo em vista as situações nas quais sua ajuda é indispensável, pois a personagem é extremamente pequena. Ainda assim, essa crítica é sutil ao colocar tal personagem como salvadora da família dos coelhos. A ratinha é corajosa e ajuda com as ferramentas que ela tem, seus dentes, que poderiam ser alusão às capacidades femininas que não eram tomadas como as responsáveis pela proteção do lar na época vitoriana, mas que através da história provaram-se valiosas.

O vigésimo primeiro conto escrito por Beatrix Potter também tinha personagens principais masculinas: The Tale of Johnny TownMouse $^{44}$ (1918). Apesar disso, Beatrix Potter se identifica com o personagem Timmy Willie, o antagonista do campo de Johnny Town-Mouse, ao explicar que "um lugar se adequa a uma pessoa, outro lugar se adequa a outra pessoa. De minha parte, eu prefiro viver no campo, como Timmy Willie"45 (POTTER, 1918).

Sua identificação explica também o nome do personagem Johnny "rato da cidade", que lida diariamente com problemas. Apesar de Timmy também enfrentar problemas com comida no campo, prefere não correr o risco que a cidade traz para animais pequenos, assim como possivelmente para Beatrix, que havia morado em ambos os espaços, sendo que na cidade sua proximidade aos animais silvestres não seria possível, e sua liberdade era maior no campo. A Revolução Industrial também transformava o cenário inglês, quando os grandes empresários reduziram ainda mais as possibilidades de independência financeira feminina, algo que Beatrix veio a conquistar no campo com a publicação de seus contos (LEAR, 2008).

O último conto de Beatrix Potter é o mais longo escrito por ela e foi dividido em pequenos capítulos. The Tale of Little Pig Robinson $^{46}$ (1930) mostra pessoas e animais convivendo

\footnotetext{
${ }^{44} \mathrm{O}$ Conto de Johnny Town-Mouse.

45 "One place suits one person, another place suits another person. For my part, I prefer to live in the country, like Timmy Willie" (POTTER, 1918).

${ }^{46} \mathrm{O}$ Conto do Porquinho Robinson.
} 
harmoniosamente devido à capacidade dos animais de adquirir alguns hábitos humanos. Apesar disso, Potter manteve sua característica diferenciação entre personagens femininos e masculinos através das aventuras de cada um. O porquinho Robinson mora com suas tias, porquinhas descritas como velhas, mas durante a narrativa sai em uma aventura, ao contrário também da gata Susan, que desde o princípio é colocada como atenciosa e dedicada à sua família humana. Durante a narrativa, Beatrix Potter faz da aventura do porquinho uma alusão à história de Robinson Crusoé, sendo revelado ao final que os leitores podem procurar saber mais com o livro de Daniel Defoe.

Assim como Robinson Crusoé, o porquinho Robinson de Beatrix Potter fica perdido em uma ilha no final do conto, algo que supostamente teria acontecido com o autor Daniel Defoe, que escreveu seu livro como uma autobiografia. Beatrix Potter se despede da escrita de seus contos também de modo autobiográfico, provavelmente, de forma a tornar seus contos suas próprias aventuras, mesmo vividas na maioria das vezes por personagens masculinos, com os quais ela também se identificava (DeWilde, 2008).

Marjorie Weir aponta que "Todas as personagens femininas de Potter são pessoalmente delicadas e preocupadas com seus papéis como excelentes mães e donas de casa meticulosas" ${ }^{47}$ (WEIR, 1989, p.162). Apesar disso, essa submissão às representações de gênero do período pode ser encarada como crítica à própria sociedade inglesa, principalmente através das punições infligidas sobre os personagens masculinos que desobedecem às femininas. Suas personagens femininas retratam o cuidado especial das mães com relação aos filhos, mas em diversas vezes essa delicadeza torna-se determinação e autoridade nas histórias.

É possível que exista nos contos de Beatrix Potter uma crítica permeada pela construção de imagens da família e dos papeis de gênero que eram tradicionais durante $\mathrm{o}$ início do século $\mathrm{XX}$ na Inglaterra. A própria autora os desafiou em sua vida, ao alcançar a independência financeira e ter se casado tarde para os padrões da época. Em seus contos existe a clara demonstração da superioridade

\footnotetext{
${ }^{47}$ All of Potter's female characters are personally fastidious and preoccupied with their roles as excellent mothers and meticulous housekeepers (WEIR, 1989, p.162).
} 
masculina especialmente quanto à liberdade de suas aventuras, enquanto as figuras femininas são retratadas em casa e com suas famílias, restritas quase exclusivamente ao espaço doméstico.

Existe sutileza em suas histórias ao abordar os temas de representatividade de gênero quando ao final de algumas narrativas, como acontece com Peter Rabbit, as mães e figuras mais velhas acabam reafirmando sua importância na educação e direcionamento dos personagens masculinos. $\mathrm{O}$ fato de existir a possibilidade da autora ter se identificado com essas personagens masculinas pode ser encarado como reconhecimento de sua suposta superioridade, mas é mais provável que signifique uma aspiração pela igualdade entre homens e mulheres, rebeldia e desejo de ser vista com a mesma consideração elevada apenas aos homens.

$\mathrm{O}$ próprio fato de Beatrix Potter ter-se tornado escritora e ilustradora e de ter mantido o registro de seus estudos sobre os animais revela seu caráter criativo e investigativo. Mas as limitações da época para as mulheres e os limites de gênero impediam-nas de viver suas próprias aventuras. Dessa forma, vemos nos contos que o desejo de aventura, perceptível na autora, é expresso nas ações das personagens masculinas, ao passo que são demonstrados os limites impostos à presença feminina no espaço público.

\section{Referências bibliográficas}

AVERY, Gillian. Beatrix Potter and Social Comedy. Bulletin John Rylands Library. Oxford, 1992.

BRESCIANI, Maria. Londres e Paris no século XIX. $5^{\text {a }}$ ed. São Paulo: editora Brasiliense, 1989. 65p.

CARVALHO, Francismar Lopes de. O conceito de representações coletivas segundo roger chartier. DHI/PPH/UEM, Maringá, v. 9, n. 1, p. 143-165, jan. 2005.

CHARTIER, Roger. Defesa e construção da noção de representação. Fronteiras, Dourados, v. 13, n. 24, p. 15-29,jul./dez. 2011

DENIPOTI, Cláudio. Apontamentos sobre a história da leitura. História e ensino, Londrina, v. 2, p. 81-91, jan. 1996. 
DEWILDE, Mandy. Victorian Restriction Restraint and Escape in the children's tales of Beatrix Potter.Tese de Mestrado. Grand Valley State University, 2008

DIAS, Daise Lilian F. Quando a mulher começou a falar: literatura e crítica feminista na Inglaterra e no Brasil. Gênero na Amazônia, Belém, n. 3, p. 143-168, jan./jun. 2013.

DUAN, Shu-Jy. A Tale of Animals: the changing images of animals in animal fantasy for children. Tese de Doutorado. Ohio State University, 1994.

FATIMA, Merizig. The Status of Women in the Nineteenth Century Victorian England. Trabalho de Conclusão de Curso. Kasdi Merbah Ouargla University, Faculty of Letters and Languages, Department of Foreign Languages, Section of English. 2013.

GUIJARRO, A. A Multimodal Analysis of The Tale of Peter Rabbit within the Interpersonal Metafunction. Journal of the Spanish Association of Anglo-American Studies. University of Ciudad Real, Espanha: 2010, p.123-140.

HENDERSON, W. O. Revolução Industrial. $2^{\mathrm{a}}$ ed. Lisboa: Editorial Verbo, 1969. 113p.

HUNT, Peter. Understanding children's literature: Key essays. 1 ed. New York: Taylor \&amp; Francis e-Library, 2002. 199 p.

IGLESIAS, Francisco. Revolução Industrial. $7^{\text {a }}$ ed. São Paulo: editora Brasiliense, 1986. 57p.

JEIKNER, Alexandra. Clothing and Identity in Frances Hodgson Burnett, Edith Nesbit and Beatrix Potter. Tese de Doutorado. Newcastle University. Philosophy. School of English Literature, Language and Linguistics. 2014.

LEAR, Linda. Beatrix Potter: The extraordinary life of a Victorian genius. Reino Unido, 2008. Disponível em https://beatrixpottersociety.org.uk/about-beatrix/

MACHADO, Lia Zanotta. Gênero, um novo paradigma?. Cadernos Pagu, v. 11, p. 107-125, jan. 1998.

MARTINS, Ana Paula Vosne. Visões do feminino: a medicina da mulher nos séculos XIX e XX. Rio de Janeiro, Fiocruz, 2004.

MORAES, Maria Lygia Quartim De. Usos e limites da categoria gênero. Cadernos pagu, v. 11, p. 99-105, jan. 1998.

PARKER, Edward. Illustration for Children's Literature. Tese de Doutorado. Rochester Institute of Technology, 1969. 
PERROT, Michelle. As mulheres ou os silêncios da história. Trad. Viviane Ribeiro. Bauru-SP: EDUSC, 2005 RÉMOND, René. O

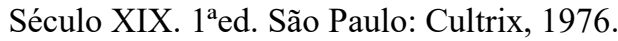

POTTER, Beatrix. The Complete Tales. $1^{\mathrm{a}} \mathrm{ed}$. Londres,Frederick Warne \& Co: 2006. 400p.

RÉMOND, René.O Século XIX - 1815 - 1914. 1ªed. São Paulo: editora Cultrix, 1990.

RODRIGUES, Dayanny. Escritos de e para mulheres no século XIX: o conceito de emancipação e a representação feminina no jornal das senhoras. Revista Outras Fronteiras, Cuiabá-MT. vol. 4, n. 1, jan/jul., 2017. P54-76.

RODRIGUES, Jorge. O trabalho feminino durante a Revolução Industrial.

Disponível

em $<$ https://www.marilia.unesp.br/Home/Eventos/2015/xiisemanadamulh er11189/o-trabalho-feminino_paulo-jorge-rodrigues.pdf $>$

SCOTT, Joan W. Gênero: uma categoria útil de análise histórica. Educação e Realidade, Porto Alegre, v. 20, n 2, jul/dez, 1995, pp. 71-99.

SEVCENKO, Nicolau. Literatura como missão: tensões sociais e criação cultural na Primeira República. $2^{a}$ ed. São Paulo: Brasiliense, 1985.

Separate Spheres and Women's Status in 19th Century England. Disponível em $<$ http://www.colorado.edu/AmStudies/lewis/1025/separatespheres.pdf $>$

SILVA, Sérgio Gomes Da. Masculinidade na história: a construção cultural da diferença entre os sexos. Psicologia: ciência e profissão, Brasília, v. 20, n. 3, set. 2000.

TEDESCHI, Losandro Antonio. As mulheres e a história: uma introdução teórica metodológica: uma introdução teórica metodológica. 1 ed. Dourados: UFGD, 2012. 144 p.

VASCONCELOS, Fabíola. O aprendizado da leitura de Imagens no livro de literatura infantil: reflexões com base na obra "Noite de Cão". Universidade Federal de Campina Grande. 2014.

VICENTE, Tânia. Metodologia da Análise de Imagens.Universidade Federal Fluminense. 
VICTORIA AND ALBERT MUSEUM. Biography of Beatrix Potter. $2016 . \quad$ Disponível em $<$ http://www.vam.ac.uk/content/articles/b/biography-beatrix-potter/>. VRIENDS, Sofie. A Strongly Marked Personality: The Discursive and Non- Discursive Posture of Beatrix Potter. 2015. 58 p. Dissertação de Mestrado - Radboud Universiteit. Disponível em: $<$ http://theses.ubn.ru.nl/bitstream/handle/123456789/604/Vriends\%2 C\%20Sofie\%204116178.pdf?sequence=1>

WEIR, Marjorie. Inside the Ring: Victorian and Edwardian Fantasy for Children. Tese de Doutorado. Simon Fraser University, 1989.

RECEBIDO EM 04/09/2018 APROVADO EM 21/10/2018 
